\title{
Impact of body mass index on presentation and outcome of acute st segment elevation myocardial infarction
}

\begin{abstract}
Background: obesity is defined as body mass index (BMI) $\geq 30 \mathrm{~kg} / \mathrm{m}^{2}$. Obesity is currently the most common metabolic disease. It is associated with many metabolic and cardiovascular diseases, thereby contributing to increased morbidity and mortality. Recent studies have described a better outcome of obese patients in the setting of acute ST segment elevation myocardial infarction (STEMI).
\end{abstract}

Objectives: to study the impact of BMI on the presentation and in-hospital outcome of acute STEMI.

Methods: a total of 140 STEMI patients were enrolled in our study, those patients were treated mainly by primary PCI. Patients were classified into two groups according to BMI; obese group with BMI $\geq 30 \mathrm{~kg} / \mathrm{m} 2$ and non obese group with BMI $<30 \mathrm{~kg} / \mathrm{m} 2$. Both groups were compared regarding presentation and in-hospital outcome.

Results: seventy six patients $(54.3 \%)$ were obese; they were significantly younger, more hypertensive, diabetic and dyslipidemic. Obese patients presented earlier $(\mathrm{P}=0.001)$ and in better Killip class than non obese $(\mathrm{P}=0.017)$. 37 non obese patients $(57.8 \%)$ had post MI complications compared to 18 obese patients $(23.7 \%)(\mathrm{P}=0.000)$, mainly heart failure, tachyarrhythmias, heart block and post MI angina. Patients with low BMI had complications 4 times more than patients with high BMI (Odds ratio $=4.416,95 \%$ C.I. from 2.138 to $9.118, \mathrm{P}<0.001$ ).

Conclusion: the current study highlights an apparent obesity paradox showing that the non-obese STEMI patients were found to have complications 4 times more than the obese patients. Caution should be taken to prevent confusion between risk marker and risk factor.
Volume 9 Issue 2 - 2017

\section{Tamer M Abu Arab, Heidi M Amin, Sherif S El \\ Zahwy \\ Department of Cardiology,Ain Shams University Hospitals,} Egypt

Correspondence: Tamer Mohamed Abu Arab, Cardiology Department, Faculty of Medicine, Ain Shams University, Lotfy El-sayed st., Abbasia square, Cairo, Egypt, Postal code: I I 566, Tel 201006004924, Fax 202248204I6,

Email tamerabuarabI@yahoo.com

Received: January 01, 1970 | Published: June 14, 2017

Keywords: STEMI, BMI, Obesity

\section{Introduction}

At the beginning of the $21^{\text {st }}$ Century, obesity has become the leading metabolic disease in the world, So that the World Health Organization (WHO) refers to obesity as the global epidemic. ${ }^{1}$ Obesity has important clinical and epidemiological implications as it is associated with many metabolic and cardiovascular diseases, a relation has been established between obesity and insulin resistance, type II diabetes, dyslipidemia, thrombosis, hypertension (HTN), atherosclerosis, and stroke. In addition, beyond being an unfavorable risk factor profile, overweight and obesity also affect heart structure and function. ${ }^{2}$ There are multiple mechanisms by which obesity leads to atherosclerotic coronary artery disease. It is associated with multiple factors which themselves are major risk factors for atherosclerosis, including abdominal obesity, insulin resistance, atherogenic dyslipidemia (i.e. high triglycerides and low high-density lipoprotein (HDL) cholesterol concentrations) and hypertension. Obesity also directly contributes to atherogenesis via the effects of some adipokines which are proinflammatory substances secreted by the adipose tissue especially interleukin-6 (IL-6), tumor necrosis factor- $\alpha$ (TNF- $\alpha$ ), angiotensin II and leptin. ${ }^{3}$

In the current environment, given the epidemic of obesity as a risk factor for coronary artery disease (CAD), there is conflict of data on the impact of body mass index (BMI) on presentation and outcome in patients presented with acute coronary syndromes (ACS). Recent studies have described a better outcome of obese patients in the clinical course of acute coronary syndrome, and obesity is associated with a trend towards a lower mortality during hospital stay. That is what called "The obesity paradox". ${ }^{46}$ Several factors and explanations stand behind this hypothesis of "obesity paradox" for example younger age at presentation with lower coronary artery disease burden, ${ }^{7,8}$ and chronic use of cardio protective drugs for other risk factors like HTN, diabetes and dyslipidemia. ${ }^{4,5}$ So we aimed to study the impact of BMI on the presentation and in-hospital outcome in patients presented with acute STEMI.

\section{Methods}

\section{Study subjects}

Out of 288 STEMI patients presented to our center in the time period from October 2014 and March 2015, 194 patients presented by chest pain duration less than 12hours and typical ECG criteria of STEMI, only 140 atients were enrolled in our study. Those patients were treated by either primary PCI to culprit vessel or thrombolytic therapy with successful reperfusion criteria (resolution of ST segment elevation $>70 \%$, resolution of chest pain and early peaking of cardiac enzymes) $)^{9}$ (Figure 1). Patients who had prior history of MI, PCI or CABG, patients who presented by cardiogenic shock (Killip class IV), patients with secondary causes of obesity (hypothyroidism, Cushing syndrome, etc.) and patients with failed thrombolytic therapy were excluded from the study. The enrolled 140 patients were classified according to their BMI into 2 groups, obese group with BMI $\geq 30 \mathrm{~kg} /$ $\mathrm{m} 2$ and non obese group with $\mathrm{BMI}<30 \mathrm{~kg} / \mathrm{m} 2$ (Figure 1). 


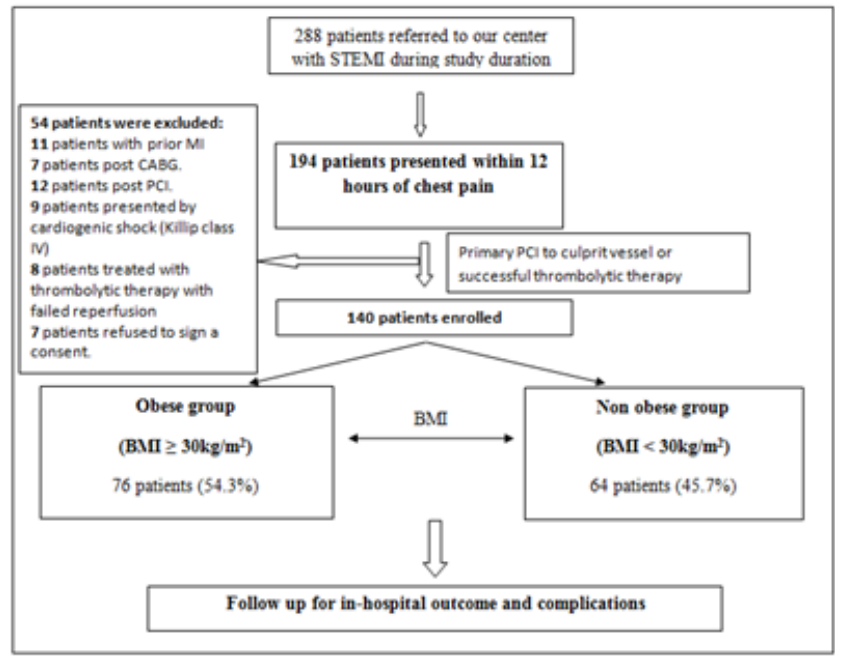

Figure I Study flowchart.

The study was approved by the local ethics committee; as it conforms to the ethical guidelines of the 1975 Declaration of Helsinki, as revised in 2013 and all patients signed a written informed consent.

\section{Study protocol}

All patients were subjected to the following: history analysis emphasizing on age, sex and presence of risk factors (smoking, hypertension, diabetes, dyslipidemia and positive family history of premature CAD), proper analysis of chest pain duration, time from symptom onset to presentation (pain to door) and time from presentation to thrombolysis (door to needle) or to balloon (door to balloon), history of any other co morbidities and presence of any of the exclusion criteria. Also detailed history of any use of cardio protective drugs (Aspirin, beta blockers, statins, RAAS blockade, etc.) was taken into consideration. Complete physical evaluation was done for all the patients on admission and during their hospital stay with recording of any abnormality especially hemodynamic data, Killip class (Class 1: patients with no abnormal clinical findings, Class 2: patients with pulmonary congestion, elevated jugular venous pressure or having $\mathrm{S} 3$ gallop, Class 3: patients with pulmonary edema, Class 4: patients with cardiogenic shock), mechanical complication (mitral regurgitation (MR), ventricular septal rupture (VSR), and cardiac tamponade) and any neurological deficit. Routine labs were done for all patients according to the clinical scenario with serial cardiac enzymes, serum creatinine and complete blood count during hospital stay to detect contrast induced nephropathy and hemoglobin drop.

I. Anthropometric measures: Body Mass Index (BMI): The height and weight were measured and used to calculate the BMI. Body mass index was defined as weight (in kilograms) divided by the square of the height (in meters) $(\mathrm{kg} / \mathrm{m} 2)$ and was used to categorize patients into two groups, obese group with BMI $\geq 30 \mathrm{~kg} / \mathrm{m} 2$ and non obese group with BMI $<30 \mathrm{~kg} / \mathrm{m} 2$. Waist circumference (WC) was measured at a level midway between the lower rib margin and the iliac crest in centimeters, ${ }^{11}$ abdominal obesity was defined as waist circumference $>102 \mathrm{~cm}$ in males, and $>88 \mathrm{~cm}$ in females. ${ }^{12}$

II. ECG: Twelve leads surface ECG was done for all patients on admission, then serial ECGs were done for signs of successful reperfusion especially patients treated by thrombolytic therapy (90 minutes post thrombolytic ECG), arrhythmias and heart block
III. Patient preparation and medications: All Patients received 300 $\mathrm{mg}$ aspirin, 600mg clopidogrel, followed by pharmacological (streptokinase 1.500 million IU) or mechanical reperfusion, for those performed primary PCI 50-100 iu/kg unfractionated heparin (UFH) was given intravenously during the procedure after control angiography (usually $70 \mathrm{iu} / \mathrm{kg}$ with GPIIb/IIIa inhibitors), with extra doses of UFH were given if activated clotting time (ACT) was less than 250seconds (hemotech device). After reperfusion therapy all patients continued on standard of care medical treatment including aspirin $150 \mathrm{mg}$ daily, clopidogrel $75 \mathrm{mg}$ daily, statins, beta blockers, and any other needed medication according to the clinical scenario.

IV. Angiographic data: Coronary angiography and subsequent needed intervention for the culprit vessel was done for each patient treated by primary PCI and within 24 hours post successful thrombolytic therapy. The following data were obtained: culprit vessel affection, TIMI flow post procedure, stent diameter, length and other vessel affection.

V. Echocardiography: was done for all patients (from the third to the fifth day post PCI) with special emphasis on ejection fraction (EF) calculated by Biplane Simpson Method (LV internal volumes), any mechanical complications (MR, VSD, pericardial effusion), segmental wall motion abnormalities and wall motion score index (WMSI) calculated to semiquantitate the extent of wall motion abnormalities. We used 16 segments; each segment was assigned a score, based on its contractility as assessed visually: normal 1 , hypokinesis 2 , akinesis 3 , dyskinesis 4 , and aneurysm 5, WMSI was calculated as the sum of wall motion scores divided by the number of the segments.

VI. Follow up for in-hospital outcome and complications: All the patients were followed up during hospital stay for: major adverse cardiac events (MACE) death, reinfarction (recurrent elevations in $\mathrm{CK}-\mathrm{MB}$ after normalization or a rise to $>50 \%$ of the prior value), or recurrent angina during hospital stay, and need for urgent revascularization. Occurrence of symptoms and signs of left ventricular dysfunction in the form of dyspnea, paroxysmal nocturnal dyspnea, fine basal rales, S3 gallop, pulmonary edema and cardiogenic shock, tachyarrhythmias as atrial fibrillation and ventricular tachycardia and bradyarrhythmias as heart block, and significant MR or VSD as mechanical complication of acute myocardial infarction. Vascular, bleeding and renal complications were also recorded. Duration of hospitalization was reported.

\section{Statistical analysis}

Data were collected, revised, coded and entered to the Statistical Package for Social Science (SPSS) version 20. The qualitative data were presented as number and percentages while the quantitative data were presented as mean, standard deviations and ranges. The comparison between two groups with qualitative data were done by using Chi-square test and Fisher exact test was used instead of Chi-square test only when the expected count in any cell found less than 5. The comparison between two groups with quantitative data and parametric distribution were done by using Independent t-test. Logistic regression analysis was used to assess the predictors of complications. The confidence interval was set to $95 \%$ and the margin of error accepted was set to $5 \%$.So the p-value was considered significant as the following: $\mathrm{P}>0.05$ : Non significant, $\mathrm{P}<0.05$ : Significant, $\mathrm{P}<0.001$ : highly significant. 


\section{Results}

One hundred forty patients out of 288 STEMI patients presented to our center during the study duration were enrolled; those patients had eligible criteria for our study design (Figure 1). Nearly all patients were treated by primary PCI and only one patient was treated by successful thrombolytic therapy followed by PCI to the culprit vessel. According to BMI patients were classified into 2 groups: the non obese group (BMI $<30 \mathrm{~kg} / \mathrm{m} 2)$ included 64 patients $(45.7 \%)$ and the obese group included 76 patients $(54.3 \%)$.

The obese patients were younger with mean age of $51.59 \pm 9.6$ years Vs $58.06 \pm 10.75$ in non obese patients $(\mathrm{P}=0.000)$, also they were more hypertensive, diabetic and dyslipidemic with no difference in other basic characteristics. Obese patients were presented earlier than non obese with mean chest pain duration of $3.63 \pm 2.78$ hours Vs $5.38 \pm 3.01$ $(\mathrm{P}=0.001)$, also they were presented in better Killip class $(\mathrm{P}=0.0102)$ in spite of having more number of anterior infarction $56.6 \% \mathrm{Vs}$ $39.1 \%(\mathrm{P}=0.039)$. No difference regarding strategy of reperfusion, door to balloon time. The rate of cardiac drug consumption before presentation was significantly higher in obese patients than non obese especially use of aspirin, Beta Blockers, RAAS blockers and statins (Table 1).

Analysis of angiographic data showed no difference in culprit vessel, number of vessel affected, and the rate of successful mechanical reperfusion (achievement of TIMI III flow) which exceeded $90 \%$ in both groups. Vessel size was bigger in obese patients (3.5 \pm 1.22 vs. $2.75 \pm 0.82 \mathrm{P}=0.001)$ (Table 2).
In-hospital outcome and complications: Compared to obese group, non - obese group showed more hemoglobin drop not related to thrombocytopenia $(\mathrm{P}=0.011)$, significant rise in serum creatinine after 48 hours $(\mathrm{P}=0.037)$, and significant $\mathrm{MR}(\mathrm{P}=0.005)$. Duration of hospitalization was shorter in obese group $(3.93 \pm 0.73$ days vs. 4.21 $\pm 0.55 \mathrm{P}=0.006$ ) (Table 3).

Eighteen patients $(23.7 \%)$ in obese group had complicated inhospital course in comparison to 37 patients $(57.8 \%)$ in non-obese group $(\mathrm{P}<0.001)$ (Figure 2). Regardless the site of infarction, obese patients were less likely to have complication than non obese $(14 \%$ vs. $44 \%$ for anterior $\mathrm{MI}$ and $36.4 \%$ vs. $66.7 \%$ for non anterior $\mathrm{MI}$ $\mathrm{P}=0.006$ and 0.010 respectively) (Table 3 ). Individual and total complications had occurred significantly less in obese group with more post MI angina, need for urgent revascularization, significant MR, tachyarrhythmias, heart block, heart failure and vascular complication occurred in non-obese group (Table 4) (Figure 3).

Relation between BMI, WC and complications: Patients with normal WC were having more complications as twice as the patients with high WC (Odds ratio $=2.192$ with $95 \%$ C.I. from 1.099 to $4.375 \mathrm{P}=0.026$ ). Also, patients with low BMI (Non obese group) were having complications 4 times more than patients with high BMI (Obese group) (Odds ratio $=4.416$ with $95 \%$ C.I. from 2.138 to 9.118 $\mathrm{P}<0.001)$. Finally, patients with combined low BMI and normal waist circumference were found to have the highest complication rate 5 times more than patients with high BMI and high waist circumference (Odds ratio $=4.86$ with $95 \%$ C.I. from 2.011 to $11.748 \mathrm{P}<0.001$ ) (Table 5).

Table I Basic characteristics of the study population

\begin{tabular}{|c|c|c|c|}
\hline Variable & $\begin{array}{l}\text { Non Obese } \\
\text { Group }(\mathrm{N}=64)\end{array}$ & $\begin{array}{l}\text { Obese Group } \\
(\mathrm{N}=76)\end{array}$ & P-value \\
\hline Age (years), mean $\pm S D$ & $58.06 \pm 10.75$ & $51.59 \pm 9.6$ & 0 \\
\hline Male gender, no (\%) & $53(82.8 \%)$ & 54 (7I. I\%) & 0.102 \\
\hline \multicolumn{4}{|l|}{ Anthropometric measures } \\
\hline Height $(m)$, mean $\pm S D$ & $1.68 \pm 0.67$ & $1.65 \pm 0.52$ & 0.346 \\
\hline weight $(\mathrm{kg})$, mean $\pm \mathrm{SD}$ & $75.39 \pm 6.94$ & $93.92 \pm 6.29$ & 0 \\
\hline BMI kg/m2, mean \pm SD & $26.78 \pm 2.3$ & $34.4 \pm 3.4$ & 0 \\
\hline Normal WC, no (\%) & $43(67.2 \%)$ & $22(28.9 \%)$ & 0 \\
\hline High WC (> $102 \mathrm{~cm}$ in males, and > $88 \mathrm{~cm}$ in females), no (\%) & $21(32.3 \%)$ & $54(71.1 \%)$ & \\
\hline Smoking, no (\%) & $49(76.6 \%)$ & $57(75.0 \%)$ & 0.83 \\
\hline Hypertension, no (\%) & $20(31.2 \%)$ & 47 (61.8\%) & 0 \\
\hline Diabetes, no (\%) & $13(20.3 \%)$ & 34 (44.7\%) & 0.007 \\
\hline Dyslipidemia, no (\%) & $9(14.1 \%)$ & $24(31.6 \%)$ & 0.015 \\
\hline Family history, no (\%) & $29(45.3 \%)$ & $37(48.7 \%)$ & 0.691 \\
\hline eGFR by MDRD $(\mathrm{mL} / \mathrm{min} / \mathrm{I} .73 \mathrm{~m} 2)$, mean $\pm \mathrm{SD}$ & $96.3 \pm 7.8$ & $97.6 \pm 8.4$ & 0.536 \\
\hline Peripheral vascular disease, no (\%) & $0(0.0 \%)$ & $0(0.0 \%)$ & NA \\
\hline \multicolumn{4}{|l|}{ Killip class, no (\%) } \\
\hline Killip I & $40(62.5 \%)$ & $64(84.2 \%)$ & 0.0102 \\
\hline Killip 2 & $17(26.5 \%)$ & $10(13.2 \%)$ & \\
\hline Killip 3 & $7(11 \%)$ & $2(2.6 \%)$ & \\
\hline Killip 4 (excluded) & $0(0 \%)$ & $0(0 \%)$ & NA \\
\hline Anterior STEMI, no (\%) & $25(39.1 \%)$ & $43(56.6 \%)$ & 0.039 \\
\hline Non anterior STEMI, no (\%) & $39(60.9 \%)$ & $33(43.4 \%)$ & \\
\hline Chest pain duration (hours) mean $\pm S D$ & $5.38 \pm 3.01$ & $3.63 \pm 2.78$ & 0.001 \\
\hline Primary PCl, no (\%) & $64(100 \%)$ & 75 (98.7\%) & 0.357 \\
\hline Streptokinase used, no (\%) & 0 & $\mathrm{I}(\mathrm{I} .3 \%)$ & \\
\hline Door-to-balloon (min.) mean $\pm S D$ & $87.5 \pm 27.8$ & $77.3 \pm 27.6$ & 0.194 \\
\hline Door-to-needle (min.) mean \pm SD & $\underline{-}$ & $34 \pm 13.5$ & NA \\
\hline Successful reperfusion, no (\%) & $59(92.18 \%)$ & 72 (94.7\%) & 0.732 \\
\hline Previous use of cardiac drugs, no (\%) & & & \\
\hline
\end{tabular}


Table Continued...

\begin{tabular}{|c|c|c|c|}
\hline Variable & $\begin{array}{l}\text { Non Obese } \\
\text { Group }(N=64)\end{array}$ & $\begin{array}{l}\text { Obese Group } \\
(N=76)\end{array}$ & P-value \\
\hline Aspirin & $7(10.9 \%)$ & $26(34.2 \%)$ & 0.001 \\
\hline Beta Blockers & $15(23.4 \%)$ & $43(56.6 \%)$ & 0 \\
\hline RAAS blockade & $3(4.7 \%)$ & 27 (35.5\%) & 0 \\
\hline Statins & $8(12.5 \%)$ & $21(27.6 \%)$ & 0.028 \\
\hline Calcium channel blockers & I (I.6\%) & $4(5.3 \%)$ & 0.24 \\
\hline Oral nitrates & 0 & I (I.3\%) & 0.357 \\
\hline
\end{tabular}

Table 2 Angiographic and interventional data

\begin{tabular}{|c|c|c|c|}
\hline Variable & Non Obese Group $(\mathbf{N}=64)$ & Obese Group ( $\mathbf{N = 7 6 )}$ & P-value \\
\hline Radial access no (\%) & $5(7.8 \%)$ & $4(5.26 \%)$ & 0.732 \\
\hline \multicolumn{4}{|l|}{ Culprit vessel: no (\%) } \\
\hline LAD & $27(42.2 \%)$ & 45 (59.2\%) & 0.131 \\
\hline LCX & 14 (2।.9\%) & II (I4.5\%) & \\
\hline $\mathrm{RCA}$ & $23(35.9 \%)$ & $20(26.3 \%)$ & \\
\hline \multicolumn{4}{|l|}{ Culprit vessel affection, no (\%) } \\
\hline Total occlusion & 46 (7I.9\%) & $47(61.8 \%)$ & 0.21 \\
\hline Significant lesion & I 8 (28.1\%) & $29(38.2 \%)$ & \\
\hline Recanalized & 0 & 0 & \\
\hline \multicolumn{4}{|c|}{ Number of vessel affected, no (\%) } \\
\hline One vessel & $23(35.9 \%)$ & $37(48.7 \%)$ & 0.307 \\
\hline Two vessels & $35(54.7 \%)$ & $34(44.47 \%)$ & \\
\hline Three vessels & $6(9.4 \%)$ & $5(6.6 \%)$ & \\
\hline \multicolumn{4}{|l|}{ Procedural details, no (\%) } \\
\hline GP Ilb/IIla inhibitors & $7(10.9 \%)$ & $5(6.7 \%)$ & 0.64 \\
\hline PTCA & II (I7.I\%) & I8 (23.6\%) & 0.746 \\
\hline Thrombus aspiration & $4(6.3 \%)$ & $3(3.9 \%)$ & 0.553 \\
\hline \multicolumn{4}{|l|}{ Stent details } \\
\hline Type Drug eluting, no (\%) & $49(76.5)$ & $61(80.2 \%)$ & 0.754 \\
\hline Stent length (mean $\pm S D)$ & $19.96 \pm 4.75$ & $19.7 \pm 6.23$ & 0.856 \\
\hline Stent diameter (mean $\pm S D)$ & $2.75 \pm 0.82$ & $3.5 \pm 1.22$ & 0.001 \\
\hline 2 stents used, no (\%) & II (I7.I\%) & $10(13.1 \%)$ & 0.73 \\
\hline Inflation pressure (mean $\pm S D$ ) & $13.6 \pm 1.58$ & $12.8 \pm 2.74$ & 0.172 \\
\hline Post deployment, no (\%) & $30(46.8 \%)$ & $43(56.6 \%)$ & 0.605 \\
\hline \multicolumn{4}{|c|}{ TIMI flow after angioplasty, no (\%) } \\
\hline TIMI 0 & $0(0 \%)$ & $0(0 \%)$ & NA \\
\hline TIMI I & $2(3.1)$ & $2(2.6 \%)$ & 0.861 \\
\hline TIMI II & $3(4.6 \%)$ & $2(2.6 \%)$ & 0.844 \\
\hline TIMI III & $59(92.18 \%)$ & $72(94.7 \%)$ & 0.732 \\
\hline
\end{tabular}

Table 3 In-hospital outcome

\begin{tabular}{|c|c|c|c|}
\hline Variable & Non Obese Group (N=64) & Obese Group ( $\mathbf{N}=76)$ & P-value \\
\hline Hemoglobin drop, no (\%) & & & 0.011 \\
\hline No drop & $50(78.1 \%)$ & $64(84.2 \%)$ & \\
\hline Mild drop (<3gm/dl) & $7(10.9 \%)$ & $12(15.8 \%)$ & \\
\hline Moderate drop (3-5 gm/dl) & $7(10.9 \%)$ & 0 & \\
\hline Severe drop (>5gm/dl) & 0 & 0 & \\
\hline Thrombocytopenia, no (\%) & $7(10.9 \%)$ & $3(3.9 \%)$ & 0.11 \\
\hline Rising of serum creatinine $>50 \%$ after 48 hours, no (\%) & $14(2 \mid .9 \%)$ & $7(9.2 \%)$ & 0.037 \\
\hline \multicolumn{4}{|l|}{ Echocardiographic data } \\
\hline EF (Biplane Simpson) mean \pm SD & $45.83 \pm 8.34$ & $47.37 \pm 8.66$ & 0.287 \\
\hline Dilated dimensions, no (\%) & $23(35.9 \%)$ & 27 (35.5\%) & 0.96 \\
\hline Wall motion score index (mean $\pm S D)$ & $2.45 \pm 0.5$ & $2.3 \pm 0.46$ & 0.067 \\
\hline Significant MR, no (\%) & $20(31.2 \%)$ & $9(11.8 \%)$ & 0.005 \\
\hline VSR, no (\%) & 0 & 0 & NA \\
\hline Effusion and tamponade, no (\%) & $0(0 \%)$ & $0(0 \%)$ & NA \\
\hline Duration of hospitalization (days) mean $\pm S D$ & $4.21 \pm 0.55$ & $3.93 \pm 0.73$ & 0.006 \\
\hline Complicated course, no (\%) & $37(57.8 \%)$ & $18(23.7 \%)$ & 0 \\
\hline \multicolumn{4}{|l|}{ Site of infarction } \\
\hline Patients with anterior $\mathrm{MI}$ having complications/total no $\mathrm{n}$ & I I/25 (44\%) & $6 / 43(14 \%)$ & 0.006 \\
\hline
\end{tabular}


Table Continued...

\begin{tabular}{|c|c|c|c|c|}
\hline \multicolumn{3}{|c|}{ Non Obese Group $(\mathrm{N}=64)$} & \multirow{2}{*}{$\begin{array}{l}\text { Obese Group }(\mathbf{N}=76) \\
12 / 33(36.4 \%)\end{array}$} & \multirow{2}{*}{$\begin{array}{l}\text { P-value } \\
0.01\end{array}$} \\
\hline $\begin{array}{l}\text { Patients with non anterior } \mathrm{MI} \text { having complications/total no with non-ant. MI, } \\
\text { no (\%) }\end{array}$ & $(n=72)$ & $\begin{array}{l}26 / 39 \\
(66.7 \%)\end{array}$ & & \\
\hline \multicolumn{5}{|l|}{ Waist circumference } \\
\hline Patients with normal waist circumference having complications, no (\%) & $(n=65)$ & $25(38.4 \%)$ & $7(10.7 \%)$ & 0.026 \\
\hline \multirow[t]{2}{*}{ Patients with high waist circumference having complications, no (\%) } & $(n=75)$ & $12(16 \%)$ & II (I4.6\%) & \\
\hline & $\mathrm{p}$ - value & 0.94 & 0.287 & \\
\hline
\end{tabular}

Table 4 Total number and types of complications in both groups

\begin{tabular}{|c|c|c|c|c|}
\hline Types of in-Hospital Complications & Total Complications & Non Obese Group & Obese Group & P-value \\
\hline Death, no (\%) & 0 & 0 & 0 & NA \\
\hline Cardiogenic shock, no (\%) & I & $\mathrm{I}(100 \%)$ & 0 & I \\
\hline Reinfarction, no (\%) & 0 & 0 & 0 & NA \\
\hline Urgent revascularization, no (\%) & 4 & $3(75 \%)$ & I (25\%) & 0.479 \\
\hline HF, no (\%) & 18 & I 3 (72.22\%) & $5(27.78 \%)$ & 0.019 \\
\hline MR, no (\%) & 29 & $20(68.97 \%)$ & $9(31.03 \%)$ & 0.009 \\
\hline VSD, no (\%) & 0 & 0 & 0 & NA \\
\hline Post MI angina, no (\%) & 13 & $10(76.92 \%)$ & $3(23.08 \%)$ & 0.018 \\
\hline Tachyarrhythmias (AF), no (\%) & 12 & II (9I.67\%) & I (8.33\%) & 0 \\
\hline Bradyarrhythmias (HB), no (\%) & 25 & $18(72 \%)$ & $7(28 \%)$ & 0.005 \\
\hline CHB, no (\%) & 12 & II (9I.67\%) & I (8.33\%) & 0 \\
\hline I st degree HB, no (\%) & 10 & $4(40 \%)$ & $6(60 \%)$ & 0.654 \\
\hline 2nd degree HB, no (\%) & 3 & $3(100 \%)$ & 0 & 0.103 \\
\hline Vascular comp. no (\%) & 4 & $4(100 \%)$ & 0 & 0.033 \\
\hline Total complications, no (\%) & 106 & $80(75.47 \%)$ & $26(24.53 \%)$ & - \\
\hline
\end{tabular}

Table 5 Relation between BMI,WC and complications

\begin{tabular}{|c|c|c|c|c|c|c|c|}
\hline & \multirow[t]{2}{*}{ B } & \multirow[t]{2}{*}{ S.E. } & \multirow[t]{2}{*}{ Wald } & \multirow[t]{2}{*}{ P-values } & \multirow[t]{2}{*}{ Odds Ratio "OD" } & \multicolumn{2}{|c|}{ 95\% C.I. for OD } \\
\hline & & & & & & Lower & Upper \\
\hline Low BMI & 1.485 & 0.37 & 16.116 & 0 & 4.416 & 2.138 & 9.118 \\
\hline Normal WC & 0.785 & 0.353 & 4.959 & 0.026 & 2.192 & 1.099 & 4.375 \\
\hline Low BMI + Normal WC & 1.581 & 0.45 & 12.336 & 0 & 4.861 & 2.011 & II.748 \\
\hline
\end{tabular}

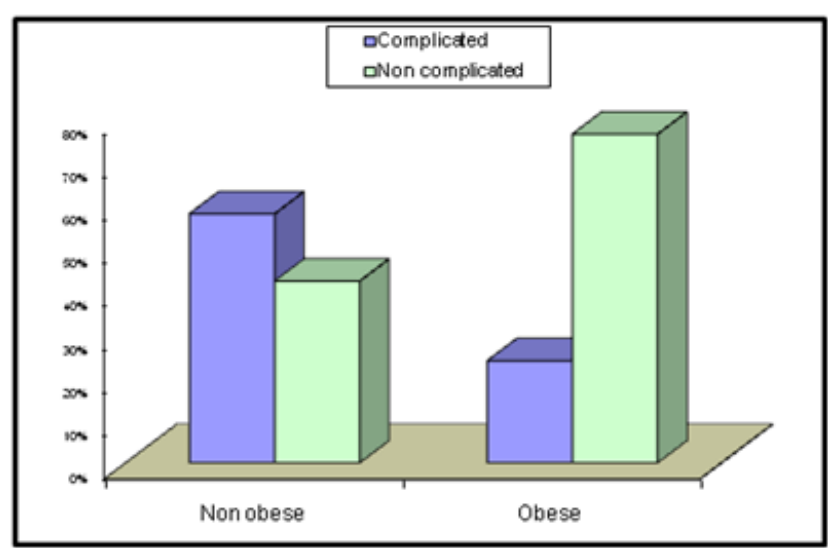

Figure 2 Comparison between the two groups as regard the in-hospital complications.

\section{Discussion}

Although the association of obesity with the development of coronary artery disease (CAD) has been well established, the effect of obesity on the morbidity and mortality of patients with acute STEMI has not been well defined. ${ }^{13,14}$ An apparent protective effect of high BMI on the outcome has been found in randomized trials in patients with unstable angina, NST- ACS and STEMI. ${ }^{4,15}$ Other studies do not support this hypothesis. ${ }^{16,17}$ In the current study, we investigated the impact of BMI and waist circumference (abdominal obesity) on presentation and in-hospital outcome of patients presenting with acute STEMI treated mainly by primary PCI. The results of our study confirmed the idea of "obesity paradox" which states the better outcome in obese patients with higher BMI $\geq 30 \mathrm{~kg} / \mathrm{m} 2$ than non obese patients. Many explanations stand behind this hypothesis and were clear in our study as well as many previous trials.

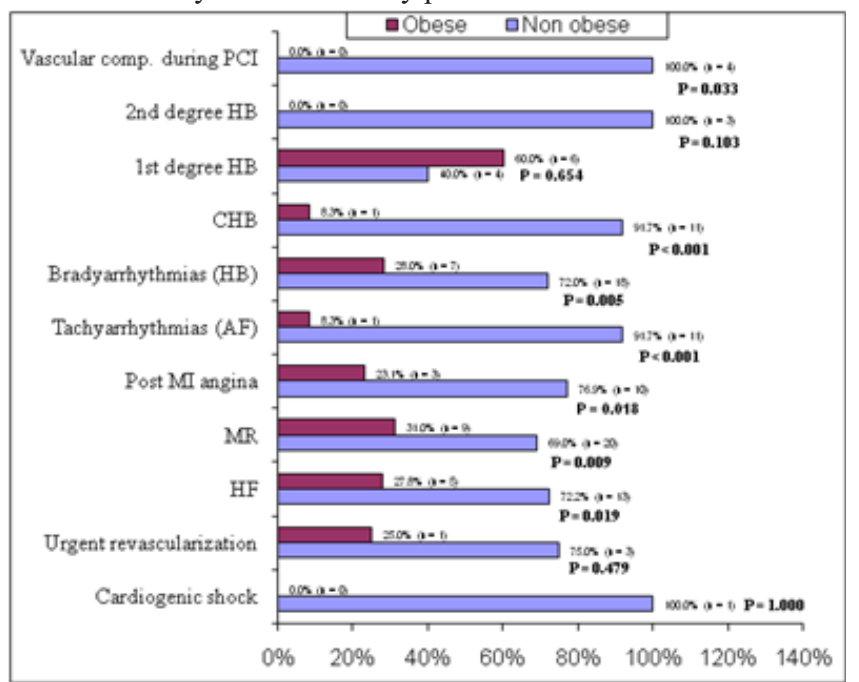

Figure 3 Total complications among the two groups.

In our study, patients in obese group were younger than non obese group; this was supported by similar works. ${ }^{7,8,18}$ Again as obesity is a risk factor for developing cardiovascular disease, obese patients in the study cohort were more likely to be hypertensive, diabetic and dyslipidemic with no difference regarding smoking and family history of premature coronary artery disease. The data on risk factors in obese 
patients presenting by acute coronary syndrome were conflicting, some agree with us, ${ }^{8,17,19}$ others showed no difference in DM and HTN between obese and non obese patients. ${ }^{2}$ Studying the history of medical treatment showed that the obese patients were more likely to be on chronic medications before presentation in the form of Acetylsalicylic acid $(34.2 \%)$, Beta blockers (56.5\%), angiotensin converting enzyme inhibitors or Angiotensin receptor blockers (35.5\%), Beta blockers $(56.6 \%)$ and statins $(27.6 \%)$. Actually, this was due to the association of obesity with other co-morbidities. The use of these cardio protective drugs in obese patients was clear in many studies. ${ }^{4-6}$ Obese patients usually present earlier to hospitals complaining of chest pain due to risk background and this helps in early diagnosis of myocardial infarction, better Killip class on presentation and of course better outcome and prognosis. In the present study they presented around 90minutes earlier than non obese patients $(\mathrm{P}=0.001)$, and the majority of them (85.5\%) were in Killip class I. The study done by Shyu et al., ${ }^{18}$ supports the same finding showing that the non obese patients had increased severity of acute myocardial infarction with killip class II or more and this was the strongest predictor of morbidity and mortality in patients presenting with acute STEMI. ${ }^{18}$

Almost all patients (except one) in our study were treated by primary PCI with no difference in the time management and rate of successful reperfusion between both groups, the only different parameter in angiographic data was the larger vessel diameter that was evident in obese patients $(\mathrm{P}=0.001)$. Similarly, Diercks et al., ${ }^{10}$ showed that the obese patients presented by ACS have larger coronary artery diameter than the non obese patients attributing this to their better outcomes. ${ }^{10}$ The relation between BMI and severity of coronary artery disease had been studied by Niraj et al., ${ }^{5}$ they showed that obese patients had a higher prevalence of diabetes, hypertension and dyslipidemia and were referred for coronary angiography at an earlier age and have a lower CAD burden supporting the hypothesis of the "obesity paradox". However, obesity alone after adjustment of comorbidities is not an independent predictor of severity of coronary artery disease and this supports our results. ${ }^{5}$

Based on the mentioned data, it was clear that obese patients had better presentation parameters than non obese patients and mostly this led to the better outcome. Non obese patients had significant rise of serum creatinine more than $50 \%$ after 48 hours from presentation and contrast exposure as well as more hemoglobin drop, these results were supported by other studies which showed that non obese patients had higher incidence of renal impairment and lower levels of hemoglobin compared to the obese patients..$^{21-23}$

Evaluating echocardiographic parameters in both groups of our study revealed no difference in EF, WMSI with significant occurrence of high grade MR in non obese patients as mechanical complication of MI. A study done by Suwaidi et al., ${ }^{24}$ revealed a trend towards better left ventricular EF in obese patients than non obese patients, ${ }^{24}$ and mostly this is due to the difference in the number of patients in both studies, other study done by Iakobishvili et al., ${ }^{16}$ showed no difference between the obese and non obese groups regarding WMSI. ${ }^{16}$

In the present study, we evaluated the incidence of in hospital complications among both groups. We found that the non obese patients had more complications than the obese patients $(57.8 \%$ vs $23.7 \% \mathrm{P}<0.001)$ regardless the site of infarction $(\mathrm{P}=0.006$ for anterior MI, $\mathrm{P}=0.010$ for non anterior $\mathrm{MI})$. This was supported by many studies that showed favorable outcome in obese patients. ${ }^{10,24}$ Das et al., ${ }^{25}$ in 2011 conducted a large study on 50,149 STEMI patients to investigate the impact of BMI on presentation, treatment and in hospital outcome, and he concluded the same finding that obese patients were younger and treated more aggressively, attributing this to the better outcomes. ${ }^{25}$

Other authors have not corroborated the protective effect of obesity in ACS. Fiol et al., ${ }^{26}$ in 2010 analyzed the prognostic value of BMI in medium-term hospital mortality in a cohort of 1,063 consecutive patients with first infarction in 15 hospitals in Spain and found no association between BMI and medium-term hospital mortality ${ }^{26}$. The criticism for this study is that Fiol et al. ${ }^{26}$ classified the patients according to BMI into many subgroups making him unable to evaluate the statistical significance between the groups regarding morbidity and mortality as risk factors presence were associated with higher mortality in every BMI category revealing no significant difference between the subgroups and this made the study in disagreement with our study and other studies that support the idea of "obesity paradox".

As regard the types of in hospital complications, we found that the occurrence of Heart failure, mitral regurgitation, post MI angina, tachyarrhythmias (AF), bradyarrhythmias (complete heart block) and vascular complications during and after PCI was significantly higher in the non obese group than the obese group while there was no significant difference between the two groups regarding cardiogenic shock, Reinfarction and urgent revascularization. No one in both groups had VSD and no deaths were present.

The study done by Diercks et al., ${ }^{10}$ in 2006 showed that obese patients had a reduced risk of congestive heart failure and recurrent ischemia when compared with non obese patients and this was supporting to our results ${ }^{10}$. In contrast, Kosuge et al., ${ }^{27}$ in 2008 studied the relationship between BMI and in-hospital outcomes in patients with STEMI who underwent primary PCI and found that the frequencies of heart failure and recurrent ischemia did not differ among the obese and non obese groups. ${ }^{27}$ Buettner et al., ${ }^{19}$ in 2007 concluded that excess triglyceride content in the heart tissue including areas of healed MI might reduce the vulnerability to atrial and ventricular arrhythmias in the obese compared with the non obese patients, ${ }^{19}$ and this may explain in part the less incidence of tachyarrhythmias in obese patients of our study $(\mathrm{P}<0.001)$. Kadakia et al. ${ }^{28}$ in 2011 showed higher incidence of vascular complications in the non obese group attributing this to smaller vessel size, and greater risk of anticoagulants over dosage. ${ }^{28}$

Bradyarrhythmias (CHB) and significant MR were higher in non obese compared to obese patients $(\mathrm{P}<0.001)$ as most of those non obese patients in our study were presented by non anterior MI $(60.9 \%)$ in which these complications are common. We assessed the relation between waist circumference (WC) and in-hospital complications. We found that patients with high waist circumference had fewer complications than patients with normal waist circumference $(30.7 \%$ vs. $49.2 \% \mathrm{P}=0.026$ ) regardless BMI. A study done by Zeller et al., ${ }^{29}$ in 2008 showed no correlation between waist circumference and in hospital complications after acute MI. ${ }^{29}$

Increased WC as part of metabolic syndrome appears to promote insulin resistance, dyslipidemia, and HTN and hence associated with incident cardiovascular events and death as shown in the metaregression analysis of 15 prospective studies that was conducted by De Koning et al. $2007 .{ }^{30}$ The relation of waist circumference to good prognosis in our study can be attributed to the same explanations of the "obesity paradox" but this relation to prognosis is still unclear and need to be assessed in more studies.

In conclusion, our study revealed that patients with normal WC had complications as twice as patients with high waist circumference $($ Odds ratio $=2.192$ with $95 \%$ C.I. $1.099-4.375, \mathrm{P}=0.026)$, and 
the non obese (low BMI) patients had complications 4 times more than the obese patients (high BMI) (Odds ratio $=4.416$ with $95 \%$ C.I. $2.138-9.118, \mathrm{P}<0.001$ ). Patients who had both factors (low BMI and normal WC) were found to have the worst outcome. They had complications nearly 5 times more than those who had high BMI and high WC (Odds ratio $=4.86$ with 95\% C.I. 2.011- 11.748, $\mathrm{P}<0.001$ )

This study supports the hypothesis of "obesity paradox" and in which obesity appears to be a risk factor for developing ACS at younger age but at the same time it seems to be associated with aggressive management and improved outcomes. Also obese patients have more detectable and potentially modifiable risk factors for cardiovascular diseases, medical treatment of the underlying clinical conditions including diabetes, hypercholesterolemia, and hypertension, eventually combined with increased exercise, change in diet, and intentional weight loss, all these might have a stronger impact on prognosis in obese when compared with non obese patients. ${ }^{19}$ Those obese patients were treated more often with statins, ACE-inhibitors, ASA and beta-blockers when compared with non obese patients, and these agents have been shown to reduce morbidity and mortality in patients with CAD. ${ }^{31}$

Other potential mediators of the improved outcome in obese patients include the endogenous cannabinoids, lower platelet count, and excess triglyceride content in heart tissue including areas of healed MI. ${ }^{19}$ Platelets seem to play a major role in the pathophysiology of acute coronary syndromes, as well as the outcome after percutaneous coronary intervention with stent implantation. ${ }^{32}$

Previous reports suggest that the non obese patients may be at higher risk due to comorbid illnesses, smaller vessel size, and greater risk for overdosed pharmacologic treatments. Some have proposed that medications used to treat ACS may affect underweight patients differently and may be limited with respect to efficacy or may cause greater toxicity in these patients in particular. ${ }^{28}$ In contrast to our results, fewer studies e.g., the one done by Aronson et al., ${ }^{8}$ in 2010 which examined the association between BMI and clinical outcomes in patients with AMI did not support the existence of any protective effect of obesity. This study revealed that the associations of BMI with the risk of morbidity and mortality were U-shaped, with higher risk observed in the lower and upper BMI categories. After adjustments for the clinical variables, LVEF and hemoglobin levels, there was no evidence for an inverse relationship between BMI and in hospital morbidity and mortality (the obesity paradox).Thus these results do not support the existence of any protective effect of obesity, and suggest that BMI above a threshold of $35 \mathrm{~kg} / \mathrm{m} 2$ should be considered an important risk factor for death as those patients with BMI $>35 \mathrm{~kg} /$ $\mathrm{m} 2$ were at increased risk for mortality and development of heart failure during follow-up. ${ }^{8}$ Our criticism to this study is that Aronson et al., ${ }^{8}$ assessed the relationship between clinical outcome especially mortality and all BMI categories showing higher mortality in the lower and upper BMI categories mainly in patients with anemia this made his study in disagreement with most of the studies that support the hypothesis of the obesity paradox.

\section{Study limitations}

BMI assessment was made only during hospital stay which does not account for the effect of the duration of obesity and recent shifts in body weight on in-hospital outcome. However, even without this additional information, our findings have a considerable clinical impact as risk is typically assessed according to actual BMI rather than BMI changes. We did not adjust for other unavailable potential confounders which may have partially explained the observed relationship between BMI and morbidity including levels of serum insulin and plasma mediators of inflammation. Finally, despite that our conclusions cannot be applied to the general population due to small sample size; they remain to be hypothesized supporting the "obesity paradox" that deserves future exploration in larger studies.

\section{Conclusion}

The current study highlights an apparent "obesity paradox" showing that the non-obese STEMI patients were found to have hospital complications 4 times more than the obese patients. Caution should be taken to prevent confusion between risk marker and risk factor.

\section{Acknowledgements}

None.

\section{Conflicts of interest}

Author declares there are no conflicts of interest.

\section{Funding}

None.

\section{References}

1. Formiguera X, Canto'n A. Obesity: epidemiology and clinical aspects. Best Pract Res Clin Gastroenterol. 2004;18(6):1125-1146.

2. Poirier P, Giles TD, Bray GA, et al. Obesity and Cardiovascular Disease: Pathophysiology, Evaluation, and Effect of Weight Loss. Circulation. 2006;113(6):898-918.

3. Yudkin JS, Stehouwer CD, Emeis JJ, et al. C-reactive protein in healthy subjects: associations with obesity, insulin resistance, and endothelial dysfunction: a potential role for cytokines originating from adipose tissue? Arterioscler Thromb Vasc Biol. 1999;19(4):972-978.

4. Mehta L, Devlin W, McCullough PA, et al. Impact of body mass index on outcomes after percutaneous coronary intervention in patients with acute myocardial infarction. Am J Cardiol. 2007;99(7):906-910.

5. Niraj A, Pradahan J, Fakhry H, et al. Severity of Coronary Artery Disease in Obese Patients Undergoing Coronary Angiography: "Obesity Paradox" Revisited. Clin Cardiol . 2007;30:391-396.

6. Shirzad M, Karimi A, Dowlatshahi S, et al. Relationship Between Body Mass Index and Left Main Disease: The Obesity Paradox. Arch Med Res. 2009;40(7):618-624.

7. Wienbergen $\mathrm{H}$, Gitt $\mathrm{AK}$, Juenger $\mathrm{C}$, et al. Impact of the body mass index on occurrence and outcome of acute ST-elevation myocardial infarction. Clin Res Cardiol. 2008;97(2):83-88.

8. Aronson D, Nassar M, Goldberg T, et al. The impact of body mass index on clinical outcomes after acute myocardial infarction. Int J Cardiol. 2010;145(3):476-480.

9. Henriques JP, Zijlstra F, van't Hof AW, et al. Primary percutaneous coronary intervention versus thrombolytic treatment: long-term follow up according to infarct location. Heart. 2006;92(1):75-79.

10. Diercks DB, Roe MT, Mulgund J, et al. The obesity paradox in nonST-segment elevation acute coronary syndromes: results from the Can Rapid risk stratification of Unstable angina patients Suppress Adverse outcomes with Early implementation of the American College of Cardiology/American Heart Association Guidelines Quality Improvement Initiative. Am Heart J. 2006;152(1):140-148.

11. Paccaud F, Schlüter-Fasmeyer V, Wietlisbach V, et al. Dyslipidemia and abdominal obesity: an assessment in three general populations. J Clin Epidemiol. 2000;53(4):393-400 
12. Despre's JP, Lemieux I, Bergeron J, et al. Abdominal obesity: the most prevalent cause of the metabolic syndrome and related cardiometabolic risk. Arterioscler Thromb Vasc Biol. 2008;28(6):1039-1049.

13. Rana JS, Mukamal KJ, Morgan JP, et al. Obesity and the risk of death after acute myocardial infarction. Am Heart J . 2004;147(5):841-846.

14. Kennedy LM, Dickstein K, Anker SD, et al. The prognostic importance of body mass index after complicated myocardial infarction. J Am Coll Cardiol. 2005;45(1):156-158.

15. Eric LE, Darren K McG, Manjushri VB, et al. Elevated Body Mass Index and Intermediate-Term Clinical Outcomes After Acute Coronary Syndromes. Am J Med. 2006;118(9):981-990.

16. Iakobishvili Z, Danicek V, Porter A, et al. Is increased body mass index associated with a cardioprotective effect after ST-segment elevation myocardial infarction? Acute Card Care. 2006;8(2):95-98.

17. Hadi HA, Zubaid M, Al Mahmeed W, et al. The prevalence and outcome of excess body weight among Middle Eastern patients presenting with acute coronary syndrome. Angiology. 2010;61(5):456-464.

18. Shyu KG, Wu CJ, Mar GY. Clinical characteristics, management and in-hospital outcomes of patients with acute coronary syndrome - observations from the Taiwan ACS Full Spectrum Registry. Acta Cardiol Sin. 2011;27:135-144.

19. Buettner HJ, Mueller C, Gick M, et al. The impact of obesity on mortality in UA/non-ST-segment elevation myocardial infarction. Eur Heart J . 2007;28(14):1694-1701.

20. Hsu HP, Jou YL, Lin SJ. Comparison of in-hospital outcome of acute ST elevation myocardial infarction in patients with versus without diabetes mellitus. Acta Cardiol Sin. 2011;27:145-151.

21. Gurm HS, Brennan DM, Booth J, et al. Impact of body mass index on outcome after percutaneous coronary intervention (the obesity paradox). Am J Cardiol. 2002;90(1):42-45.

22. Kang WY, Jeong MH, Ahn YK, et al. Obesity paradox in Korean patients undergoing primary percutaneous coronary intervention in ST-segment elevation myocardial infarction. J Cardiol. 2010;55(1):84-91.
23. Lawler PR, Filion KB, Dourian T, et al. Anemia and mortality in acute coronary syndromes: a systematic review and meta-analysis. Am Heart $J$. 2013;165(2):143-153.

24. Suwaidi JA, Wright RS, Grill JP, et al. Obesity is associated with premature occurrence of acute myocardial infarction. Clin Cardiol . 2001;24(8):542-547.

25. Das SR, Alexander KP, Chen AY, et al. Impact of body weight and extreme obesity on the presentation, treatment, and in-hospital outcomes of 50,149 patients with ST-segment elevation myocardial infarction results from the NCDR (National Cardiovascular Data Registry). J Am Coll Cardiol. 2011;58(25):2642-2650.

26. Fiol M, Amezaga R, Aros R, et al. Body mass index in the prognosis of first myocardial infacrtion. Medicina clinica. 2011;135(14):631-636.

27. Kosuge M, Kimura K, Kojima S, et al. Impact of body mass index on in-hospital outcomes after percutaneous coronary intervention for ST segment elevation acute myocardial infarction. Circ $J$. 2008;72(4):521-525.

28. Kadakia MB, Fox CS, Scirica BM, et al. Central obesity and cardiovascular outcomes in patients with acute coronary syndrome: observations from the MERLIN-TIMI 36 trial. Heart. 2011;97(21):1782-1787.

29. Zeller M, Steg PG, Ravisy J, et al. Relation between body mass index, waist circumference, and death after acute myocardial infarction. Circulation. 2008;118(5):482-490.

30. De Koning L, Merchant AT, Pogue J, et al. Waist circumference and waist-to-hip ratio as predictors of cardiovascular events: meta-regression analysis of prospective studies. Eur Heart J. 2007;28(7):850-856.

31. Fox KA, Poole-Wilson P, Clayton TC, et al. 5-year outcome of an interventional strategy in non-ST-elevation acute coronary syndrome: the British Heart Foundation RITA 3 randomised trial. Lancet. 2005;366(9489):914-920.

32. Mueller C, Roskamm H, Neumann FJ, et al. A randomized comparison of clopidogrel and aspirin versus ticlopidine and aspirin after the placement of coronary artery stents. Circulation. 2000;101(6):590-593. 